\title{
Ruptured postinfarction ventricular septal aneurysm causing chronic congestive cardiac failure Detection by two-dimensional echocardiography
}

\author{
JOHN D STEPHENS, * MARTIN R GILES, SEAMUS O BANIM \\ From the Department of Cardiology, St Bartholomew's Hospital, London
}

SUMMARY We report a 62-year-old man who presented with a two-month history of severe congestive failure. The onset of his symptoms was not associated with chest pain. Two-dimensional echocardiography showed a large aneurysm of the ventricular septum in which there was a defect.

The presence of a postinfarction ruptured ventricular septal aneurysm was confirmed by subsequent cardiac catheterisation and surgery.

Rupture of the interventricular septum is an uncommon complication of acute myocardial infarction. ${ }^{1}$ It occurs most commonly within the first seven days after infarction ${ }^{2}{ }^{3}$ and usually causes distinct haemodynamic deterioration frequently proceeding to cardiogenic shock.

This case report describes an unusual presentation of post-myocardial infarction ventricular septal defect, with unique features detected by real-time twodimensional echocardiography.

\section{Case report}

Over a period of 10 days, a 62-year-old man experienced increasing dyspnoea and ankle swelling not associated with chest pain. He was treated with digitalis and a diuretic with some initial symptomatic improvement. Two months later he was admitted to hospital in severe congestive cardiac failure. Because of the presence of a praecordial systolic murmur, a diagnosis of mitral regurgitation was made and he was referred to St. Bartholomew's Hospital for further investigation.

\section{CLINICAL EXAMINATION}

He was slightly dyspnoeic at rest. The pulse was 90 per minute, regular, and of normal quality. The blood

ॠPresent address: Department of Cardiology, The London Hospital, Whitechapel, London E1 1BB. pressure was $115 / 80 \mathrm{mmHg}$. The jugular venous pulse was visible to the angle of the jaw. There was a palpable left parasternal impulse and a systolic thrill. On auscultation there was a loud systolic murmur, maximal at the left third intercostal space. There was pronounced hepatomegaly and moderate ankle and sacral oedema.

The electrocardiogram showed changes of a previous inferior myocardial infarction.

On the chest $x$-ray film there was cardiomegaly with intense pulmonary venous congestion and septal oedema.

Real-time, two-dimensional echocardiography was performed using a Varian 3000 instrument. Apical, left and right ventricular long axis and multiple short axis views were obtained. ${ }^{4}$ Normal left ventricular geometry and wall motion was seen in the long axis view. There was no prolapse of the mitral valve cusps. The apical, right ventricular long axis and short axis views showed the presence of a large ventricular septal aneurysm bulging into the right ventricle (Fig. 1 and 2). Thinning of the aneurysmal part of the interventricular septum was observed in the apical and right ventricular long axis views (Fig. 2). In the short axis view at the level of the papillary muscles (Fig. 1) a defect in the wall of the aneurysm was observed. From multiple short axis views it was seen that the aneurysm extended from the level of the mitral valve to the level of the insertion of the papillary muscles. These views showed preserved left ventricular wall motion in regions not involved in the aneurysm. M-mode echocardiography showed minimal right ventricular enlargement as the only abnormality. 

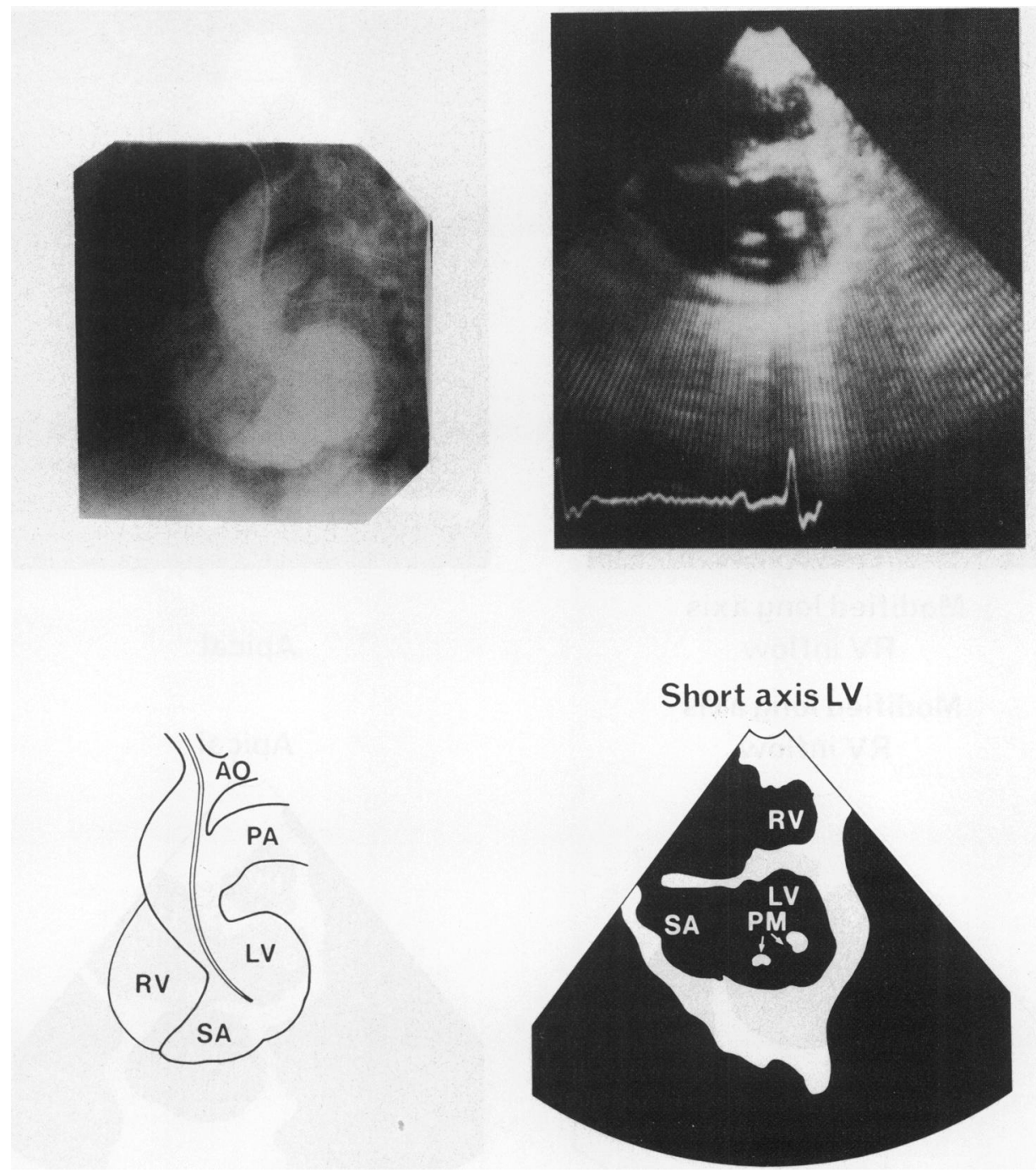

Fig. 1 Left: Left ventricular cineangiogram; left oblique view. The catheter is situated in the left ventricle $(L V)$. $A$ septal aneurysm $(S A)$ is seen. Contrast fills the right ventricle $(R V)$ and pulmonary artery $(P A)$. Right: Two-dimensional echocardiogram showing the septal aneurysm at the level of the papillary muscles $(P M)$ with a defect in its wall. $A O$, aorta.

Cardiac catheterisation was subsequently performed. Right heart pressures were raised (right atrium, mean $16 \mathrm{mmHg}$; right ventricle $75 / 20 \mathrm{mmHg}$; pulmonary artery $75 / 25 \mathrm{mmHg}$ ). The left ventricular end-diastolic pressure was $25 \mathrm{mmHg}$. There were no valve gradients. There was a left-to-right shunt at ventricular level (pulmonary:systemic flow ratio, 3.0/1). Left ventricular cineangiography (left and right anterior oblique views) confirmed the presence of a large ventricular septal aneurysm originating from the posteroinferior portion of the septum. An associated ventricular septal defect was also confirmed, with early filling with contrast of the right ventricle and pulmonary artery (Fig. 1).

There was no impairment of ventricular contraction in regions other than the aneurysm. There was minimal mitral regurgitation. Coronary angiography showed the presence of a major stenosis in the left anterior descending and circumflex vessels. The right coronary artery was totally occluded near its orifice. 


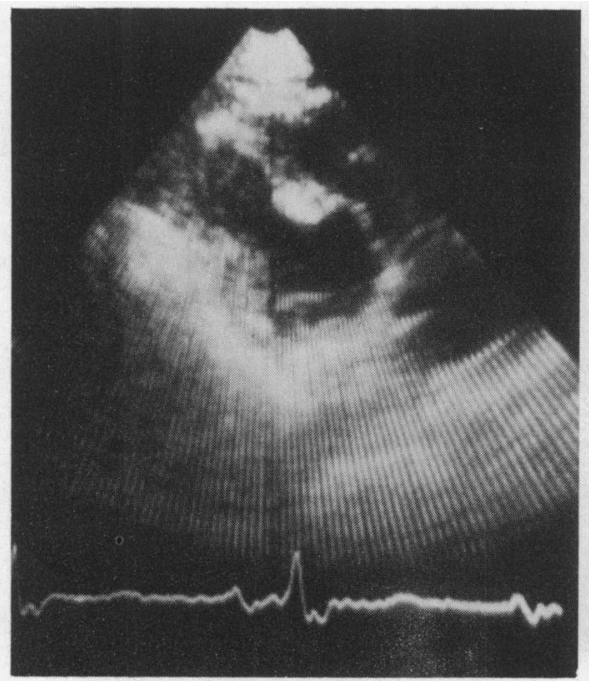

Modified long axis RV inflow

\section{Modified long axis}

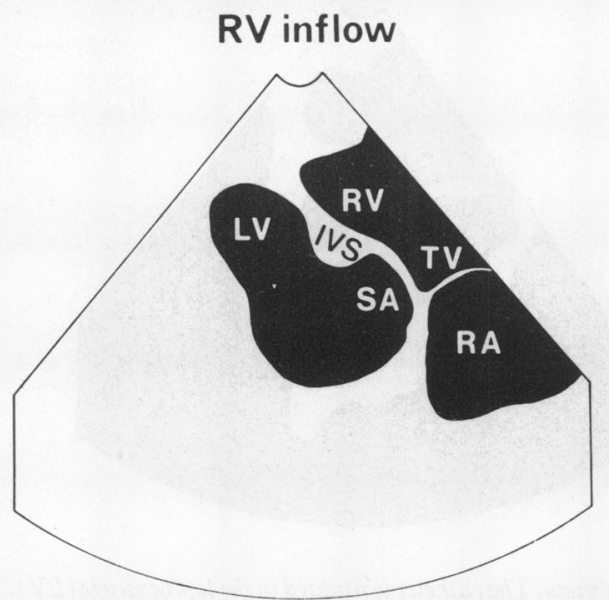

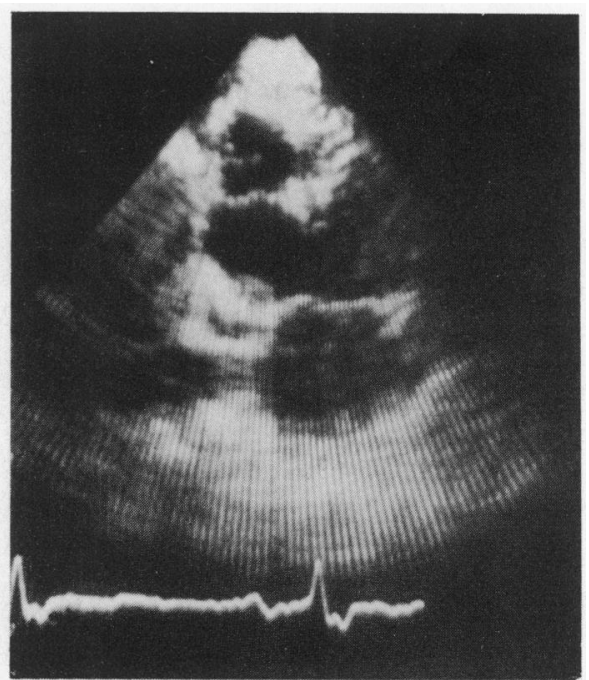

\section{Apical}

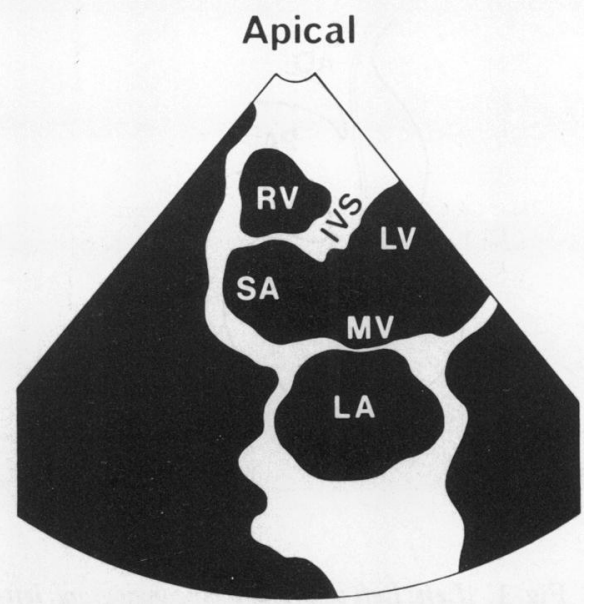

Fig. 2 Two-dimensional echocardiograms showing the septal aneurysm $(S A)$ in two views in which thinning of the interventricular septum (IVS) in the region of the aneurysm is seen. $L V$, left ventricle; $R V$, right ventricle; $T V$, tricuspid valve; $R A$, right atrium; $L A$, left atrium; $M V$, mitral valve.

The patient subsequently underwent operation at which a ruptured ventricular septal aneurysm was found situated posteroinferiorly. Part of the inferior surfaces of the right and left ventricles had the appearance of previous myocardial infarction. The aneurysm was excised and the defect repaired with a dacron patch. Coronary artery vein grafts to the left anterior descending and circumflex vessels were performed.

Multiple complications occurred postoperatively and the patient died after three weeks.

\section{Discussion}

Coronary artery disease is a frequent cause of chronic congestive cardiac failure. Irreversible ischaemic damage to the myocardium may, if generalised, directly produce global hypo- or akinesia. Alternatively, localised damage may lead to aneurysm formation which may indirectly cause irreversible damage to the functioning myocardium. ${ }^{5}$ The patient described in this report illustrates an unusual mechanism 
by which localised ischaemic damage may lead to severe chronic congestive cardiac failure; that of severe chronic left ventricular volume overload consequent upon a postinfarction ventricular septal defect.

Of further interest is the associated ventricular septal aneurysm. Aneursyms of the left ventricle have been previously described ${ }^{2} 3$ in association with postinfarction ventricular septal defects but they have usually involved the apical or anterolateral regions. Such aneurysms may exacerbate the adverse haemodynamic effects of the shunt by compromising the ability of the left ventricle to compensate for the resulting volume overload. To our knowledge discrete postinfarction aneurysm of the ventricular septum has not been previously reported. In this patient rupture of the aneurysm did not produce a catastrophic decline in left ventricular performance but was tolerated for a relatively long period. This was probably the result of a relative sparing of the left ventricle by the infarct which may have involved, as well as the septum, the right ventricle to a greater extent.

An important feature of this case was the ability of two-dimensional echocardiography to show the aneurysm localised to the septum, the preservation of left ventricular wall motion in other regions, and the absence of mitral valve prolapse. Further, a defect in the wall of the aneurysm was seen and was in accordance with the observation of Scanlan et al. ${ }^{6}$ who reported a case of postinfarction ventricular septal defect diagnosed by two-dimensional echocardiography.

Thus, in our patient, two-dimensional echocardio- graphy accurately predicted the diagnosis and differentiated a ruptured ventricular septal defect from mitral regurgitation. It may therefore prove a useful technique in the assessment of similar clinical problems.

\section{References}

1 Friedberg CK. Diseases of the heart. 3rd ed. Philadelphia: WB Saunders, 1966: 855.

2 Giulani ER, Danielson GK, Pluth JR, Odyniec NA, Wallace RB. Postinfarction ventricular septal rupture. Surgical considerations and results. Circulation 1974; 49: 455-9.

3 Kaplan MA, Harris CN, Kay JH, Parker DP, Magidson O. Postinfarction ventricular septal rupture. Clinical approach and surgical results. Chest 1976; 69: 734-8.

4 Tajik AJ, Seward JB, Hagler DJ, Mair DD, Lie JT. Twodimensional real-time ultrasonic imaging of the heart and great vessels: technique, image orientation, structure identification and validation. Mayo Clin Proc 1978; 53: 271-303.

5 Stephens JD, Dymond DS, Spurrell RAJ. Radionuclide and haemodynamic assessment of left ventricular functional reserve in patients with left ventricular aneurysm and congestive cardiac failure. Response to exercise stress and isosorbide dinitrate. Circulation 1980; 61: 536-42.

6 Scanlan JG, Seward JB, Tajik AJ. Visualization of ventricular septal rupture utilizing wide-angle two-dimensional echocardiography. Mayo Clin Proc 1979; 54: 381-4.

Requests for reprints to Dr J D Stephens, Department of Cardiology, The London Hospital, Whitechapel, London E1 1BB. 